\title{
FORÇAMENTO DE BROTAÇÃO EM BATATA CULTIVAR ARACY (IAC-2) PARA O TESTE DE PRÉ-CULTURA ( $\left.{ }^{(}\right)$
}

\author{
HELOISA MORATO DO AMARAL $\left({ }^{2}\right)$, NEWTON DO PRADO GRANJA $\left({ }^{3}\right)$, \\ HILARIO DA SILVA MIRANDA FILHO $\left({ }^{3,6}\right)$, JOSE ALBERTO CARAM \\ DE SOUZA DIAS $\left({ }^{4,6}\right)$ e HUMBERTO BORTOLETTO $\left({ }^{5}\right)$
}

\begin{abstract}
RESUMO
A implantação do teste da pré-cultura é condição necessária para a melhoria da certificação da batata-semente no Brasil. Esse teste permite o aprimoramento da determinação da sanidade do material produzido, principalmente no tocante à porcentagem de plantas contaminadas pelo virus do enrolamento da folha da batata (VEFB), um dos principais fatores limitantes da produção de batata-semente, e de outros problemas fitossanitários transmissiveis pelo tubérculo. Um dos principais pontos de restrição a seu emprego é o tempo necessário para a obtenção de leitura final efetiva Para determinar o melhor método de forçamento de gemas que permitisse a leitura final, foi realizado em 1983, no município de Tietê (SP), um ensaio com diferentes métodos de forçamento, empregando o cultivar Aracy (IAC-2), proveniente de campo com cerca de $20 \%$ de infecção do tubérculo-mãe pelo VEFB. Os tratamentos utilizados foram os seguintes: (1) testemunha; (2) tratamento de tubérculos com $\mathrm{CS}_{2}, 30 \mathrm{~cm}^{3} / \mathrm{m}^{3}$ de câmara, durante $48 \mathrm{~h}$; (3) imersāo de gemas em solução contendo $1 \mathrm{ppm}$ de ácido giberélico por 10 minutos; (4) idem, solução contendo $2 \mathrm{ppm}$; (5) tratamento 2 + tratamento 3; (6) tratamento 2 + tratamento 4 . Foram realiza-
\end{abstract}

(1) Trabalho parcialmente financiado polo Convenio EMBRAPA/S.A.A. Apresentado no XXIV Congresso Brasileiro de Olericultura, realizado em Jaboticabal (SP) de 16 a 21 de julho de 1984. Recebido para publicação em 4 de junho de 1984.

$\left({ }^{2}\right)$ Serviço de Controle de Qualidade, Departamento de Sementes, Mudas e Matrizes, CATI. SP.

${ }^{3}$ ) Seção de Raízes e Tubérculos, Instituto Agronómico, IAC, Caixa Postal 28, 13100 Campinas,

(C) Seçāo de Virologis Fitotécnica, IAC.

${ }^{5}$ ) Serviço de Produçāo de Mudas, Departamento de Sementes, Mudas e Matrizes, CATI.

(6) Com bolsa de suplementação do CNPq. 
das cinco observações, até 50 dias após o plantio, dos seguintes pontos: porcentagem de emergência, altura das plantas, número de folhas na haste principal e de hastes por gema, porcentagem de VEFB e facilidade de leitura. $O$ plantio foi realizado em canteiros, com terra esterilizada, plantando gemas em espaçamento de $0,25 \times 0,10 \mathrm{~cm}$. Os tratamentos que propiciaram germinação precoce foram os que utilizaram a combinação dos dois produtos $\left(\mathrm{CS}_{2}\right.$ e ácido giberélico), sendo a diferença diminuída no decorrer das leituras. $O$ tratamento 5 apresentou plantas em condiçōes ideais de leitura num período de tempo mais curto.

Termos de indexação: batata-semente; pré-cultura; forçamento de brotação.

\section{INTRODUCÃO}

Segundo BARBIER (1955), o teste de pré-cultura tem por finalidade determinar a sanidade de lotes de tubérculos de batata (Solanum tuberosum L.) destinados à multiplicação, pela leitura de sintomas, principalmente de doenças viróticas, em plantas originadas de tubérculos amostrados desses lotes, determinação essa feita an tecipadamente à distribuição do material. Isoladamente ou mais comumente complementando testes de laboratório para a determinação do estado sanitário da batata-semente, testes semelhantes sao empregados nos principais centros produtores de batata-semente. Para tanto podem ser empregados tubérculos inteiros ou gemas, conforme DARLING \& WERNER (1968) e HIDDEMA (1972). SOUZA DIAS (1984) sugere o emprego do nome de "teste de pré-plantio" quando as plantas se destinam exclusivamente à determinação da sanidade dos lotes, reservando o nome "pré-cultura" quando se objetiva também o aproveitamento dos tubérculos produzidos

Para CUPERTINO (1972), um dos principais problemas limitantes da produção de batata-semente com alta sanidade nas condições brasileiras é o causado pelo vírus do enrolamento da folha da batata (VEFB), cuja infecção da estação corrente muitas vezes se dá sem a manifestação de sintomas. Assim, somente as inspeções no decorrer da cultura não podem assegurar a sanidade de lotes destinados à certificação. Os sintomas de infecção do tubérculo-mãe pelo VEFB, contudo, são bastante claros e severos, nas plantas dele originadas, induzindo sensivel redução na produção (CUPERTINO \& COSTA, 1970).

$\mathrm{Na}$ determinação da sanidade de campos destinados à produção de batata-semente já há informações positivas da validade do teste de pré-cultura, bem como sobre a maneira de se proceder à amostragem (MALLOZZI, 1976; MIRANDA FILHO \& MALLOZZI, 1976, e SOUZA DIAS et alii, 1984).

Para que o teste de pré-cultura possa ser efetivamente utilizado pelos serviços de certificação, não somente para a batata-semente básica e regis- 
trada, como previsto pela atual legislação de certificação da batata-semente, mas também para a batata-semente certificada, faltam na literatura brasileira maiores informações que demonstrem sua facilidade e aplicabilidade. A principal restrição feita ao teste é o tempo necessário para a determinação final da sanidade, e a conseqüente certificação ou não do lote.

Um dos fatores que permitem a avaliação mais rápida é o forçamento da brotação da gema ou tubérculo a ser avaliado. As informações constantes da literatura brasileira sobre o forçamento da brotação em batata, segundo ABRAMIDES \& CASTRO (1975), REGHIN (1982) e SCIVITTARO \& BOOK (1963) concentram-se no tratamento de tubérculos inteiros, destinados à produção comercial.

Neste trabalho, procurou-se determinar a metodologia a ser empregada para, tratando-se gemas do cultivar Aracy à pré-cultura, obter no menor tempo possível plantas que permitam leitura efetiva de sua sanidade.

\section{MATERIAL E MÉTODOS}

Foram utilizados no ensaio tubérculos do cultivar Aracy (IAC-2) produzidos em campo com cerca de $20 \%$ de contaminação do tubérculo-mãe com o VEFB, onde não foi processada a erradicação das plantas doentes, colhidos em 25 de abril de 1983.

O delineamento utilizado foi de blocos ao acaso, com seis tratamentos e quatro repetições. Os tratamentos foram os seguintes: 1: Testemunha; 2: Tratamento de tubérculos com bissulfureto de carbono $\left(\mathrm{CS}_{2}\right), 30 \mathrm{~cm}^{3} / \mathrm{m}^{3}$ de câmara, durante 48 horas; 3: Imersão de gemas em solução de ácido giberélico, a $1 \mathrm{ppm}$, por 10 minutos; 4: Idem, solução a $2 \mathrm{ppm}$; 5: Tratamento $2+$ tratamento 3, e 6: Tratamento $2+$ tratamento 4 .

$\mathrm{O}$ tratamento com $\mathrm{CS}_{2}$ foi realizado em câmara hermética, em $2 \mathrm{e}$ 3 de maio de 1983, utilizando tubérculos inteiros. A 4 de maio, foram coletadas gemas da parte apical dos tubérculos de todos os tratamentos com colheres apropriadas, feitas na Seção de Raízes e Tubérculos, e que permitem a retirada de pedaços uniformes e esféricos, com peso médio de 12 gramas.

A solução de ácido giberélico foi preparada nas concentraçōes indicadas a partir de produto comercial A imersão das gemas foi feita, utilizando-se sacos de polietileno, "tipo rede". As gemas dos tratamentos 1 e 2 foram imersas em água pelo mesmo período.

O plantio foi realizado no Serviço de Produção de Mudas de Tietê, DSMM, CATI, em canteiros, com mistura de duas partes de solo arenoso, uma de solo argiloso e uma de matéria orgânica, esterilizada com brometo de 
metila. Foram plantadas cerca de 50 gemas por canteiro, em espaçamento de $0,25 \times 0,10 \mathrm{~m}$, em linhas de dez gemas, para facilidade de leitura.

A porcentagem de emergência das plantas foi assinalada aos 8,22 , 36 e 50 dias após o plantio (DAP). Quando da terceira leitura, foram anotados a altura e o número de folhas presentes em 100 plantas por tratamento, tomadas ao acaso, o número médio de hastes e a porcentagem de plantas com sintomas de contaminação pelo VEFB. Aos 50 DAP foi feita a determinação final de sanidade das plantas

$\mathrm{Na}$ análise da variância, a determinação de diferenças entre tratamentos, dado o pequeno número de contrastes em estudo e a pequena importância da ocorrência de erro tipo I, em comparacão à de um erro tipo II, foi utilizado o teste $t$, quando $F$ foi significativo.

\section{RESULTADOS E DISCUSSÃo}

A utilização de gemas em vez de tubérculos inteiros na realização do teste de pré-cultura deve-se a dois fatos Os tubérculos a serem avaliados são coletados em estádio fisiológico jovem, podendo a coleta ser antecipada à colheita do campo. Assim, a maior penetração de produtos, quando tratados por imersao, aliada à maior concentraçao do produto próximo às gemas a serem ativadas e à própria indução de forçamento causado pelo ferimento, favorecerá a emergência precoce de gemas em relação à de tubérculos inteiros. O segundo fator importante é o da menor necessidade de espaço requerida pelo plantio de gemas. O solo para execução do teste deve estar livre de patógenos que possam mascarar seus resultados, e esta exclusão, quer pelo tratamento de canteiros, quer pelo plantio em recipientes individuais, com solo tratado, será tão mais fácil quanto menor a área ou a quantidade de solo requeridas.

$\mathrm{Na}$ avaliação dos resultados sobre os tratamentos de gemas, devem ser considerados basicamente os aspectos relacionados com a precocidade de emergencia das plantas e a facilidade no reconhecimento de sintomas de viroses, pontos que não são necessariamente coincidentes.

Os resultados obtidos são apresentados no quadro 1 .

Com exceçâo da avaliação realizađa aos $8 \mathrm{DAP}$, quandō somente ō tratamento combinando o efeito do $\mathrm{CS}_{2}$ com a maior dose do ácido giberélico teve emergência superior aos demais, todos os tratamentos superaram a testemunha em todas as leituras. Com o decorrer do tempo experimental, houve diminuição nas diferenças, percentual e estatística, entre os tratamentos que receberam produtos forçadores, mas um distanciamento sempre crescente em relação à testemunha (Figura 1 ). As poucas plantas do tratamento testemunha que emergiram até os 50 DAP sofreram provavelmente algum 


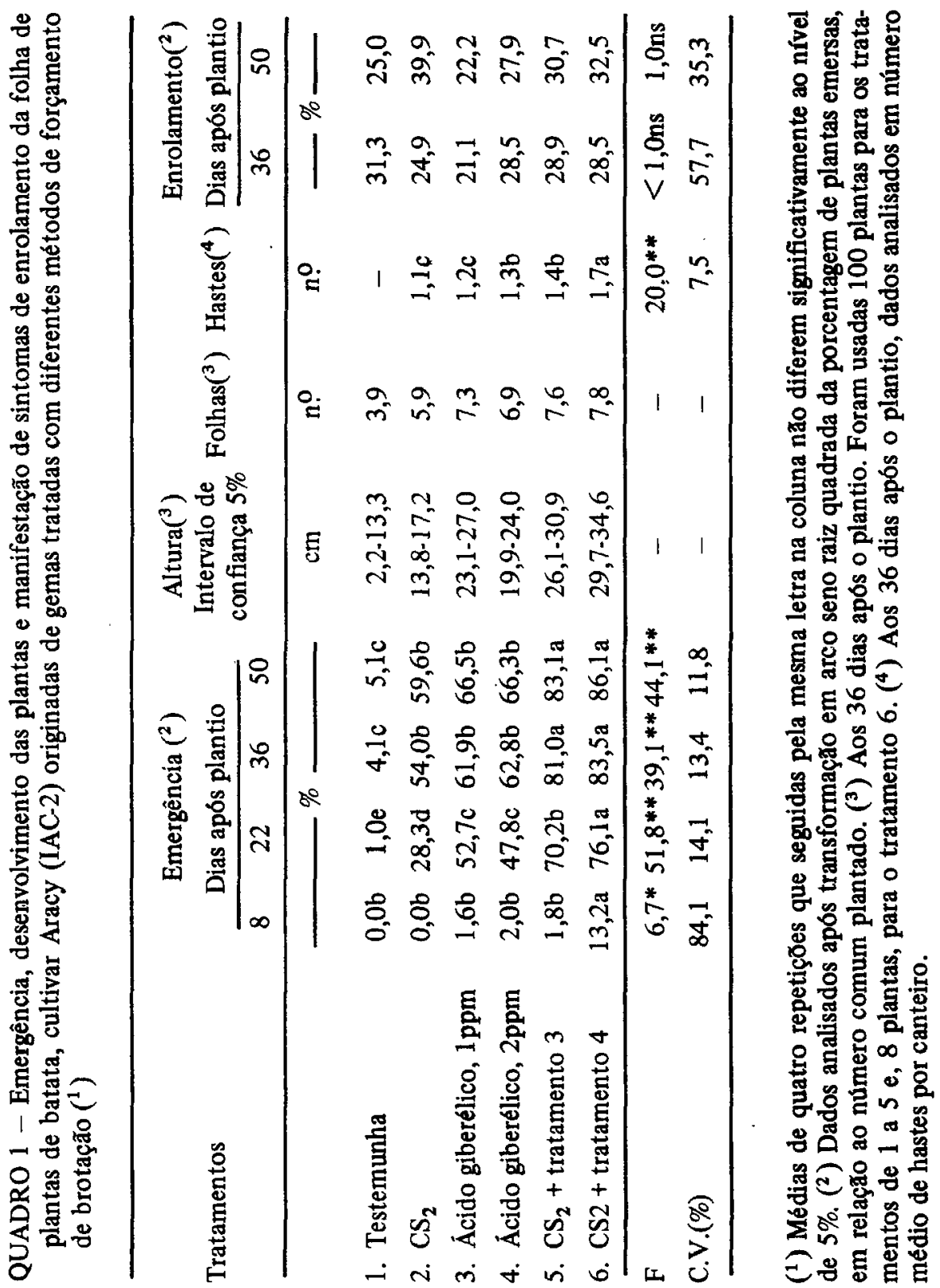


efeito, fisiológico ou patológico, que as predispôs a ter sua dormência interrompida precocemente. Os tratamentos com ácido giberélico foram superiores ao $\mathrm{CS}_{2}$ apenas até os $22 \mathrm{DAP}$, havendo, contudo, notável interação entre os produtos, contribuindo melhor para a interrupção da dormência.

Nenhum dos tratamentos teve emergência próxima da totalidade. Para isso contribuiu o excesso de precipitação pluvial, que ocasionou apodrecimento dẹ gemas, sem, contudo, prejudicar a avaliação e interpretação dos dados.

Devido às grandes diferenças entre as alturas de plantas e número de folhas dentro das parcelas, não foi feita a análise estatística das observações. Os intervalos de confiança, todavia, obtidos da observação de 100 plantas ao acaso por tratamento e das poucas plantas emersas da testemunha, sugerem que não deve haver diferenças dentro dos diferentes grupos de tratamento ( 2 ; 3 e $4 ; 5$ e 6) quanto a esta caracteristica, mas que a altura também é afetada pelo tipo de tratamento utilizado, de acordo com o produto ou combinação de produtos. O tratamento 6 , já aos $36 \mathrm{DAP}$, apresentou grande número de plantas estioladas, com hastes frágeis e finas, completamente acamadas, dificultando a contagem do número de plantas e o reconhecimento de sintomas do VEFB. A fragilidade das hastes e seu acamamento foi influenciada mais pelo aumento no número de hastes deste tratamento, significativamente

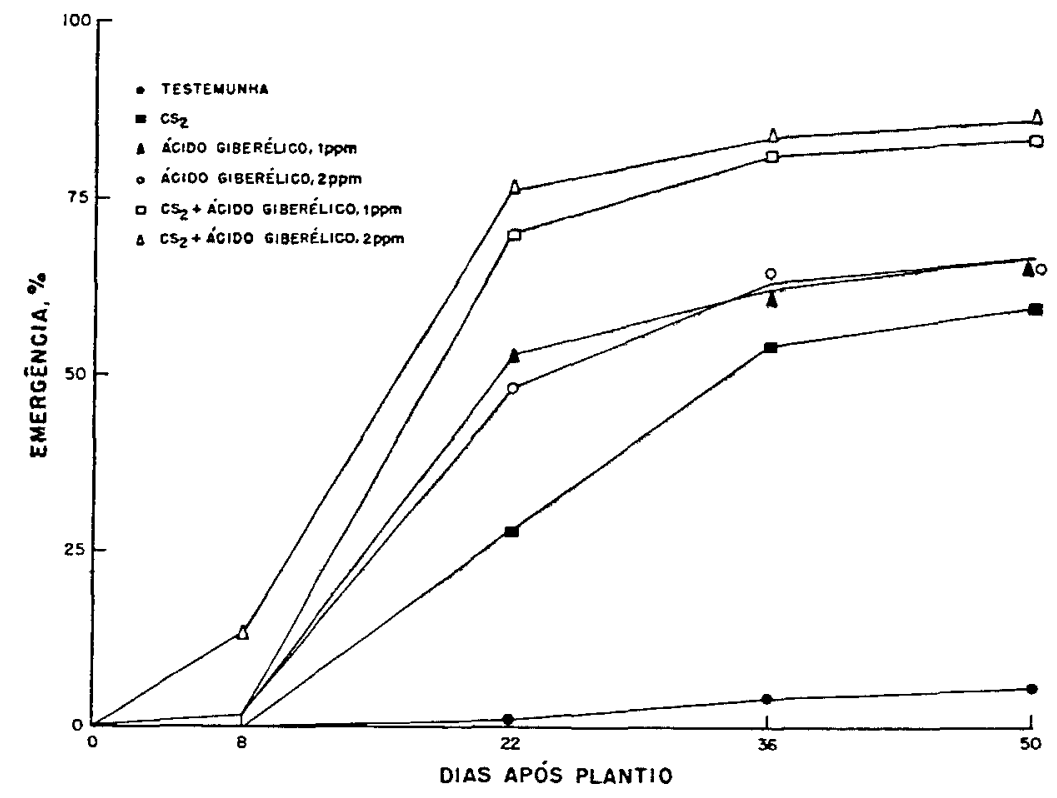

FIGURA 1 - Porcentagem de emergência em dias após o plantio 
maior que todos os outros, do que pela altura das plantas. O aumento do número de hastes é característica indesejável, por dificultar a avaliação da emergência e determinação do percentual de sanidade do material em avaliação. $O$ tratamento 5 não apresentou os mesmos problemas de estiolamento e acamamento que o 6, embora fosse sempre o seguinte, percentual e estatisticamente. No entanto, apenas o tratamento 2 apresentou todas as plantas completamente eretas.

O número de folhas, determinado na haste maior quando mais de uma ocorrida na mesma gema, parece ser pouco influenciado pelos tratamentos forçadores. Isso indicaria distribuição desequilibrada de elaborados nos tratamentos com maior média de altura, se se tratasse de plantas destinadas à produção, o que não ocorre no caso presente.

Como era previsível, a distribuição de plantas com VEFB não apresentou diferenças significativas entre os tratamentos, não havendo associação com a .porcentagem de emergência. Não foi feita interpretação estatística dos dados entre as duas leituras, sendo as diferenças pequenas, com exceção da havida no tratamento 2 , devido ao aumento de plantas que atingiram o estádio ideal de leitura. Note-se que o tratamento 2 foi o que teve maior diferença no percentual de emergência entre as duas épocas.

O 'Aracy' é de tuberização tardia, o que ocasiona que seus tubérculos estejam fisiologicamente mais jovens do que os de outros cultivares escolhidos na mesma ocasião. Para ele, pela porcentagem de emergência e pela não dificuldade que apresentou para a leitura dos sintomas do VEFB, o melhor tratamento foi a combinação do emprego do $\mathrm{CS}_{2}$ e a imersão em solução de $1 \mathrm{ppm}$ de ácido giberélica Outros cultivares, com diferentes precocidades de tuberização, deverão ter reação diferencial aos forçadores de brotação para o teste da pré-cultura.

\section{CONCLUSÕES}

Os resultados obtidos confirmam a possibilidade da implantação do teste de pré-cultura para a melhoria da certificação da batata-semente no Brasil.

A combinação do tratamento de tubérculos inteiros de batata com $\mathrm{CS}_{2}, 30 \mathrm{~cm}^{3} / \mathrm{m}^{3}$ de câmara, durante $48 \mathrm{~h}$, e posterior retirada de gemas e seu tratamento por imersão em soluçao de ácido giberélico a $1 \mathrm{ppm}$, durante dez minutos, propiciou, para o 'Aracy' (IAC-2), a melhor emergência e relativa facilidade para a contagem de plantas e avaliação de sintomas. Maiores informações são necessárias para cultivares de diferentes precocidades de tuberização. 
A pequena diferença entre percentagens de plantas com sintomas claros de contaminação com o VEFB, determinadas aos 36 a $50 \mathrm{DAP}$, torna evidente que a leitura final efetiva pode ser realizada na primeira data indicada.

Naiores informações envolvendo a coleta de amostras antecipadamente a colheita dos campos de produção, bem como de tratamentos que reduzam a percentagem de apodrecimentos, devem ser obtidas, em nivel varietal.

\section{SUMMARY}

EVALUATION OF METHODS FOR BREAKING THE DORMANCY OF POTATO SEED PIECES, CV. ARACY (IAC-2) FOR THE DETERMINATION OF POTATO SEED QUALITY

For the Brazilian conditions, the determination of the quality of a potato field, grown for seed purposes cannot be done based only in field inspections. A post control method is already recommended, based on the removal of spheric seed pieces from the crown end of tuber samples and their planting for further determination of their phytosanitary quality. In order to determine the best way for breaking the dormancy of seed pieces of the cv. Aracy (IAC-2) a late cultivar, which ought produce plants of easy determination of secondary infection with the potato leafroll virus (PLRV), a trial was carried out with six treatments in 1983, at Tietê, State of São Paulo, Brazil. The treatments were: 1 - check control; 2 - whole tubers treated with $\mathrm{CS}_{2}\left(30 \mathrm{cc} / \mathrm{m}^{3}\right.$ of chamber during 48 hours) and posterior removal of the eyes; 3 - immersion of the seed pieces in a solution containing $1 \mathrm{ppm}$ of gibberellic acid (G.A.); 4 - the same, in a 2 ppm G.A. solution; 5 - treatment 2 plus treatment 3; and 6 - treatment 2 plus treatment 4 . The treatment 5 gave the best results. It is discussed the influence of the seed piece treatment in the percentage of a perfect stand, in four consecutive observations, spaced of two weeks; in the height of the plants; in the numbers of leaves in the major stem; in the number of stems per seed piece and in the development of PLRV symptoms.

Index terms: seed potato; post-control; breaking of dormancy.

\section{REFERENCIAS BIBLIOGRÁFICAS}

ABRAMIDES, E. \& CASTRO, J.L. de. Métodos para forçar a brotação da batatinha. In: REUNIÃO ANUAL DA SBPC, 27., Belo Horizonte, 1975. Resumos. p. 607.

BARBIER, R. Préculture des plantes de pommes de terre. s.1. Fédération Nationale des Producteurs de Plantes de pommes de terre, 1955. 30p. 
CUPERTINO, F.P. Disseminação do vírus do enrolamento da folha em multiplicações sucessivas da batata-semente em São Paulo. Piracicaba, ESALQ, USP, 1972.59 p. Tese (Doutoramento)

\& COSTA, A.S. Avaliação das perdas causadas por virus na produção da batata. I. Virus do enrolamento da folha. Bragantia, Campinas, 31:337-345, 1970.

DARLING, H.M. \& WERNER, H.O. Seed potato certification. In: SMITH, O. Potatoes: production, storing, processing. West Port, Avi Publishing Company Inc., 1968. p.318-327.

HIDDEMA, J. Inspection and quality grading of seed potatoes. In: de BOKX, J.A., ed. Viruses of potatoes and seed - potato production. Wageningen, Centre for Agricultural Publishing and Documentation, 1972. p.206-215.

MALLOZZI, P. Aplicação do método de pré-cultura nos testes virológicos de batata-semente. Revista da Sociedade Brasileira de Fitopatologia, Campinas, 9:38, 1976. (Resumo).

MIRANDA FILHO, H.S. \& MALLOZZI, P. Amostragem para o teste de précultura. Revista da Sociedade Brasileira de Fitopatologia, Campinas, 9:38, 1976. (Resumo)

REGHIN, MARYE Y. Estudo do forçamento da brotação em batatas-semente (Solanum tuberosum L.). Botucatu, UEPJM, FCA, 1982.132p. Dissertação (Mestrado)

SCIVITTARO, A. \& BOOCK, O.J. Experiências sobre ativação da brotação das batatas-semente pelo bissulfureto de carbono. Bragantia, Campinas, 22:XIX-XXV, 1963. (Nota, 6)

SOUZ A DIAS, J.A.C. Manutenção do estoque básico de variedades de batata nacionais aproveitando a avaliação de sanidade dos campos de produção. Piracicaba, ESALQ, USP, 1984. 82 p. Tese (Mestrado)

; TEIXEIRA, P.R.M.; RAMOS, V.J.; COSTA, A.S. Avaliaça da sanidade de um campo de batata-semente combinada com a seleção de material livre de vírus. In: CONGRESSO PAULISTA DE FITOPATOLOGIA, 4, Campinas,.1981. Resumos. p. 64-65. 